\title{
Nutritional status of 2-6 year old children of Kankabati grampanchayat, Paschim Medinipur district, West Bengal, India
}

\author{
Nirmalya Kumar Sinha ${ }^{1}$, Kartik Maiti ${ }^{2}$, Pradip Samanta ${ }^{3}$, Dulal Chandra Das ${ }^{4}$, Priyanka Banerjee ${ }^{1}$
}

Sri Lanka Journal of Child Health, 2012; 41(2): 60-64

\begin{abstract}
Objective: To assess the prevalence of undernutrition (underweight, stunting and wasting) among preschool children of Kankabati grampanchayat, Paschim Medinipur, West Bengal, India
\end{abstract}

Methods: The study was a community based, cross-sectional survey carried out among 410 Bengali Hindu low socioeconomic preschool children (198 boys and 212 girls) of 2 to 6 years. The height and weight of each child were taken. The results were analyzed by $\mathrm{Z}$ score values according to height for age, weight for age and weight for height with reference to NCHS.

Results: The overall prevalence of undernutrition among these children was: underweight $47 \%$, stunting $43 \%$ and wasting $24 \%$. Severe (below -3 $\mathrm{Z}$ score) underweight, stunting and wasting was $13.7 \%, 16.3 \%$ and $7.9 \%$ respectively. Prevalence of underweight was higher in boys $(45.5 \%)$ than girls $(43.9 \%)$; stunting and wasting were also higher in boys (44.9\% stunting and $25.3 \%$ wasting) than girls (41.5\% stunting and $22.6 \%$ wasting).

Conclusion: The findings of the present study revealed widespread prevalence of undernutrition among preschool children of Kankabati grampanchayat, Paschim Medinipur, West Bengal, India.

(Key words: Preschool children; community health; undernutrition)

\section{Introduction}

Nutritional status is a major determinant of the health and well-being among children and there is no debate on the importance of the study of child nutritional status according to spatial and temporal

\footnotetext{
${ }^{1}$ Department of Nutrition, ${ }^{2}$ Department of Zoology, ${ }^{3}$ Department of Microbiology, ${ }^{4}$ Associate Professor, Department of Botany, Raja N L Khan Women's College, Midnapore, India,
}

(Received on 10 June 2011: Accepted on 20 July 2011) dimension ${ }^{1}$. Malnutrition continues to be a major public health problem throughout the developing world, particularly in South Asia and sub-Saharan Africa $^{2-6}$. Preschool children constitute the most vulnerable segment of any community. Their nutritional status is a sensitive indicator of community health and nutrition ${ }^{7}$. Globally it is estimated that among preschool age children in developing countries nearly 183 million are underweight, 226 million are stunted and 67 million are wasted ${ }^{8}$. About $70 \%$ of the World's stunted children aged under five years live in Asia ${ }^{9}$. Since independence one of the greatest problems facing India is malnutrition among under five years old children. India has the highest occurrence of childhood malnutrition in the world ${ }^{\mathbf{1 0}}$. As per the report of National Nutrition Monitoring Bureau and National Institute of Nutrition ${ }^{11}$ nearly $43.8 \%$ children suffer from moderate degrees of protein energy malnutrition in the form of marasmus and kwashiorkor, $8.7 \%$ suffer from extreme forms of malnutrition and only $9.9 \%$ of the children are normal. Therefore, childhood undernutrition is a serious health problem in India including West Bengal. There is lack of sufficient data available on health profile and nutritional status among preschool children in Paschim Medinipur district. The present study is an attempt in this regard to evaluate the level of undernutrition, stunting and wasting among preschool children of Kankabati grampanchayat of Paschim Medinipur district in West Bengal.

\section{Method}

The Kankabati grampanchayat of Paschim Medinipur district is 23 metres above sea-level and $127 \mathrm{~km}$ away from Kolkata towards the west. The total area studied was $35.97 \mathrm{sq} \mathrm{km}$. The study design was a community based, cross-sectional type and we investigated the area from May 2010 to April 2011. The investigation is based on 2-6 year old children. We visited the study area several times during the stipulated period. In our observation, out of 3,875 families only 1,535 families have 3,824 children of 2-6 years old. Out of 3,824 children 1,938 are boys and 1,886 are girls of which only 410 (198 boys and 212 girls) children were taken for investigation by systemic random sampling method ${ }^{\mathbf{1 2}}$. The socioeconomic 
status of each subject was assessed by Kuppuswami's socioeconomic status scale revised by Mishra \& Singh, $2003^{13}$.

The questionnaire was the tool for collecting data. The questionnaire was based on demographic information, anthropometric data and personal hygiene. Each child was identified by name, age and sex. Date of birth was obtained from the birth certificates in order to ensure the quality of data. The anthropometric measurements including height and weight of each subject were measured using standard techniques ${ }^{\mathbf{1 4}}$. The height and weight measurements were recorded to the nearest $0.1 \mathrm{~cm}$ and $0.5 \mathrm{~kg}$ respectively. Body Mass Index (BMI) of each child was calculated according to 'Quatelets' Index. All the children were examined clinically for signs of nutritional deficiencies and other morbidities.

The nutritional status of the children was evaluated using age and sex specific values of height and weight from the National Centre for Health Statistics (NCHS) reference data ${ }^{15}$. The indices of undernutrition such as stunting, underweight and wasting were calculated by Z-score using the reference values of height-for-age, weight-for-age and weight-for-height of NCHS standards, respectively. Z-scores were calculated following the standard formula:

$\mathrm{X}-$ Median of NCHS Standard deviation of NCHS where $\mathrm{X}$ is an individual value. Three $\mathrm{Z}$-scores were calculated: height-for-age Z-score (HAZ), weight-for-age Z-score (WAZ) and weight-forheight Z-score (WHZ). The following scheme was utilized to define undernutrition:

Stunting: $\mathrm{HAZ}<-2$, underweight: WAZ $<-2 \&$ wasting: $\mathrm{WHZ}<-2$.

Children with Z-score below -2 of any of the indices were considered to be undernourished and the children with Z-score below -3 were considered to be severely undernourished.

The statistical analyses were performed using Statistical Package for Social Science, Version 10.0 (SPSS software). For anthropometric data, a software package based on NCHS database as provided with EP16. One-sample t test and t test for two independent samples were completed. The data was collected after obtaining the necessary approval from the Parents and Grampanchayat authority. The purpose of the study was also explained to the Grampanchayat authority.

\section{Results}

The distribution of the study subjects by age and sex is presented in Table I.

Table 1

Age and sex wise distribution of anthropometric indices among children

\begin{tabular}{|c|c|c|c|c|c|c|}
\hline \multirow{2}{*}{$\begin{array}{c}\text { Age } \\
\text { (years) }\end{array}$} & \multicolumn{2}{|c|}{ Number } & \multicolumn{2}{c|}{ Weight (kg) } & \multicolumn{2}{c|}{ Height (cm) } \\
\cline { 2 - 7 } & Boys & Girls & Boys & Girls & Boys & Girls \\
\hline 2 & 23 & 26 & $9.49 \pm 1.85$ & $9.42 \pm 1.94$ & $76.74 \pm 9.68$ & $77.48 \pm 7.53$ \\
\hline 3 & 32 & 41 & $12.02 \pm 1.62$ & $11.99 \pm 2.12$ & $90.92 \pm 6.54$ & $90.65 \pm 6.59$ \\
\hline 4 & 66 & 77 & $13.34 \pm 2.23$ & $12.89 \pm 1.89$ & $96.42 \pm 6.49$ & $94.79 \pm 5.41$ \\
\hline 5 & 47 & 46 & $14.54 \pm 2.33$ & $14.07 \pm 2.14$ & $102.16 \pm 6.41$ & $101.01 \pm 8.11$ \\
\hline 6 & 30 & 22 & $15.90 \pm 2.37$ & $15.91 \pm 2.11$ & $108.12 \pm 6.66$ & $109.48 \pm 7.03$ \\
\hline
\end{tabular}

Data are represented as Mean $\pm S D$

A total of 410 children including $198(49.3 \%)$ boys and $212(51.7 \%)$ were included in this study. We found that children were not achieving their normal weight and height in reference to NCHS standards. Figures 1-3 show that both boys and girls are underweight and shorter compared to the NCHS reference data and both boys and girls are almost similar in height and weight.

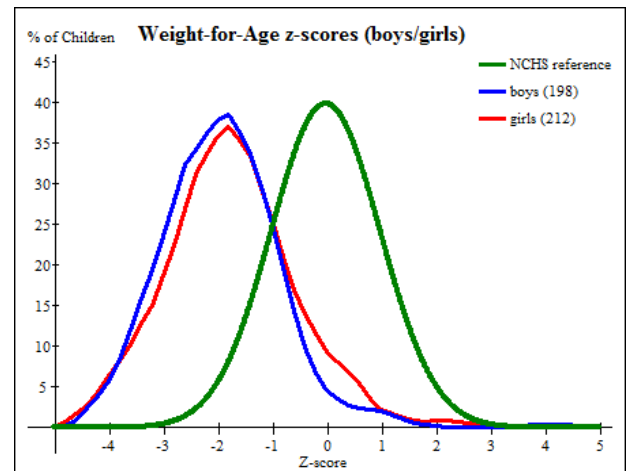

Figure 1 


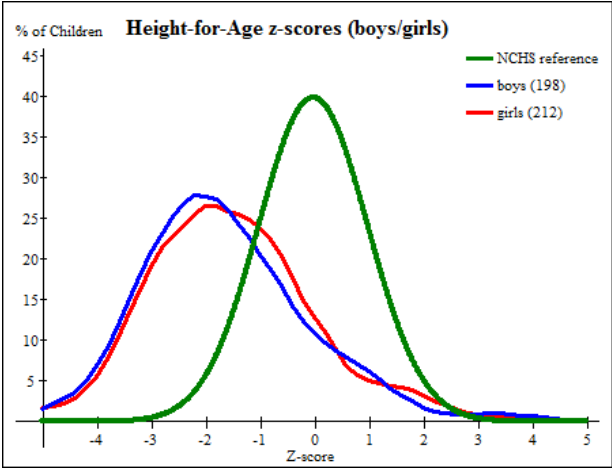

Figure 2

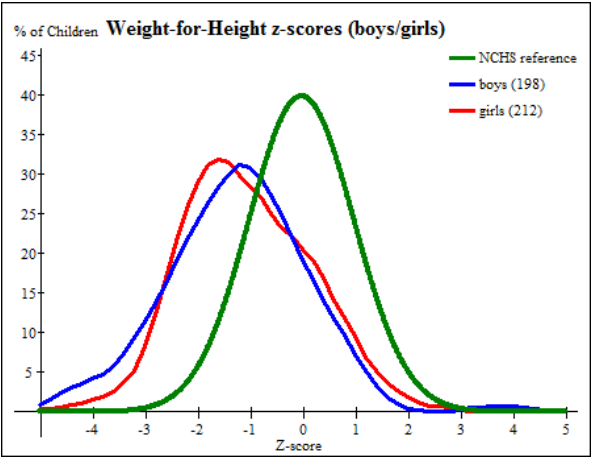

Figure 3

The distribution of the study subjects according to $\mathrm{Z}$ score is shown in Table 2.

Table 2

Distribution of 2-6 years Children according to $Z$ - score

\begin{tabular}{|c|c|c|c|c|c|c|c|c|c|c|}
\hline $\begin{array}{c}\text { Age Group } \\
\text { (years) }\end{array}$ & \multicolumn{2}{|c|}{2} & \multicolumn{2}{|c|}{3} & \multicolumn{2}{c|}{4} & \multicolumn{2}{c|}{5} & \multicolumn{2}{c|}{6} \\
\hline & Boys & Girls & Boys & Girls & Boys & Girls & Boys & Girls & Boys & Girls \\
\cline { 2 - 12 } & $\mathrm{N}=23$ & $\mathrm{~N}=26$ & $\mathrm{~N}=32$ & $\mathrm{~N}=41$ & $\mathrm{~N}=66$ & $\mathrm{~N}=77$ & $\mathrm{~N}=47$ & $\mathrm{~N}=46$ & $\mathrm{~N}=30$ & $\mathrm{~N}=22$ \\
\hline \multirow{2}{*}{ Underweight } & 15 & 9 & 13 & 18 & 28 & 35 & 23 & 22 & 21 & 9 \\
& $(65.2)$ & $(34.6)$ & $(40.6)$ & $(43.9)$ & $(42.4)$ & $(45.5)$ & $(48.9)$ & $(47.8)$ & $(70.0)$ & $(40.9)$ \\
\hline \multirow{2}{*}{ Stunting } & 13 & 14 & 8 & 14 & 31 & 32 & 25 & 22 & 12 & 6 \\
& $(56.5)$ & $(53.9)$ & $(25.0)$ & $(34.2)$ & $(46.9)$ & $(41.6)$ & $(53.2)$ & $(47.8)$ & $(40.0)$ & $(27.3)$ \\
\hline \multirow{2}{*}{ Wasting } & 4 & 5 & 8 & 9 & 17 & 15 & 13 & 12 & 8 & 7 \\
$(17.4)$ & $(19.2)$ & $(25.0)$ & $(21.9)$ & $(25.8)$ & $(19.5)$ & $(27.7)$ & $(26.1)$ & $(26.7)$ & $(31.8)$ \\
\hline
\end{tabular}

Figure in parentheses are percentage

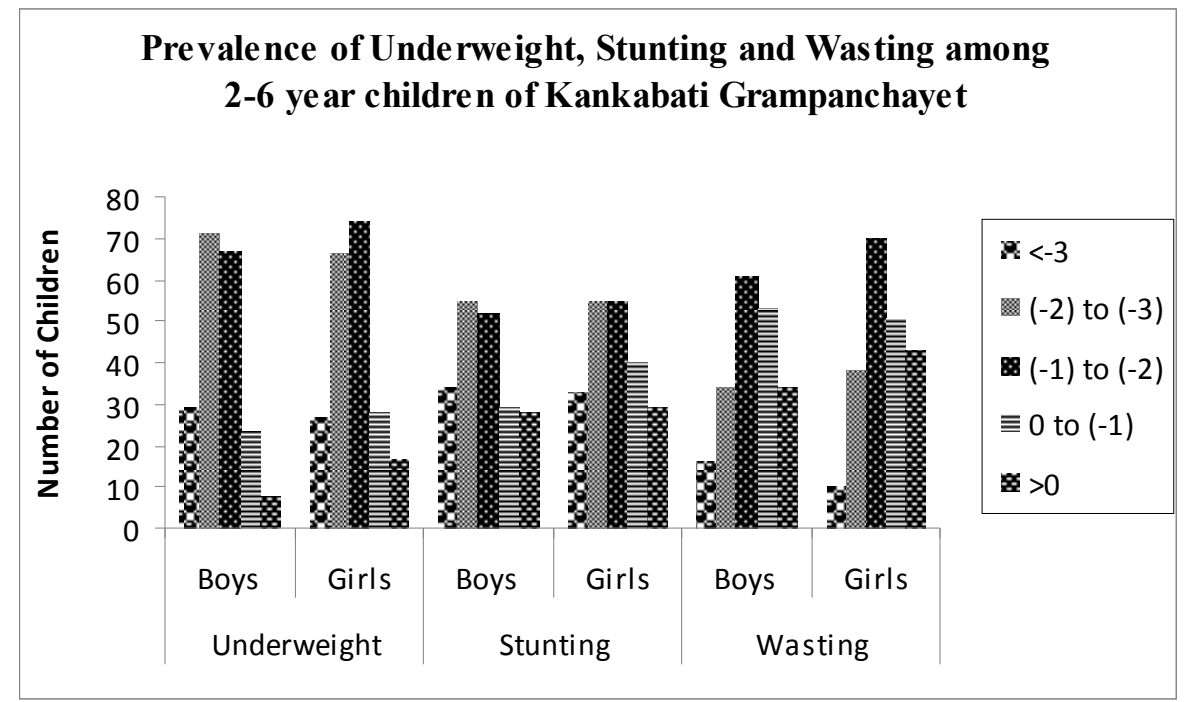

Figure 4

Figure 4 shows the prevalence of underweight, stunting and wasting among 2-6 year old children of Kankabati Grampanchayet. Moderate underweight $(Z$ score between -2 to -3$)$ was higher in boys $(35.86 \%)$ than girls $(31.13 \%)$ and severe underweight ( $\mathrm{Z}$ score $<3$ ) was higher in boys $(14.65 \%)$ than girls $(12.74 \%)$. The prevalence of moderate stunting ( $\mathrm{Z}$ score between -2 to -3 ) was found to be almost similar in boys $(27.78 \%)$ and in girls $(25.94 \%)$ but severe stunting was higher in boys $(17.17 \%)$ than girls $(15.57 \%)$. Moderate wasting was almost similar in girls $(17.92 \%)$ and boys $(17.17 \%)$ but in severe wasting boys $(8.08 \%)$ were more affected than girls $(4.72 \%)$. 
Table 3

Distribution of preschool children according to $\mathrm{Z}$ - score (Main result)

\begin{tabular}{|c|c|c|c|}
\hline & Boys & Girls & $\begin{array}{c}\text { Overall } \\
\text { (sex \& age } \\
\text { combined) }\end{array}$ \\
\cline { 2 - 4 } & $\mathbf{N = 1 9 8}$ & $\mathbf{N}=\mathbf{2 1 2}$ & $\mathbf{N = 4 1 0}$ \\
\hline Underweight & $100(50.5)$ & $93(43.9)$ & $193(47)$. \\
\hline Stunting & $89(44.9)$ & $88(41.5)$ & $177(43.2)$ \\
\hline Wasting & $50(25.3)$ & $48(22.6)$ & $98(23.9)$ \\
\hline
\end{tabular}

Table 3 shows the overall distribution of preschool children according to $\mathrm{Z}$ score. Stunting and wasting (below $-2 \mathrm{Z}$ score) were found in $89(44.9 \%)$ and $50(25.3 \%)$ boys respectively and these values were higher than girls $88(41.51 \%)$ stunting and $22.64 \%$ (wasting). Overall 193 (47.07\%), 177 (43.17\%), 98 $(23.90 \%)$ children were underweight, stunted, and wasted respectively, according to the reference criteria ( $\mathrm{Z}$ score below -2 ) recommended by WHO (Table 3). Severe ( $Z$ score below -3 ) underweight, stunting and wasting were found in $56(13.66 \%)$,
67 (16.34\%) and 26 (6.34\%) of preschool children respectively.

\section{Discussion}

Undernutrition is increasingly recognized as a prevalent and important health problem in many developing countries including India. This problem has serious long term consequences for the child and adversely influences development of a nation ${ }^{\mathbf{1 6}}$. India has more than 47 million stunted children, $29 \%$ of the global total. Around $30 \%$ of Indian children are born with low birth weight and more than half $(52 \%)$ of the mothers are also underweight $^{17}$. It has been suggested that, as undernutrition is a function of both food deprivation and disease, which are in turn the consequences of poverty, anthropometric indices can serve only as proxies for evaluating the prevalence of undernutrition among children ${ }^{18}$.

According to WHO (1995) classification assessment for severity of malnutrition by percentage prevalence ranges is shown in Table 4.

Table 4

Classification assessment for severity of malnutrition by percentage prevalence ranges ${ }^{19}$

\begin{tabular}{lcccc}
\hline \multicolumn{1}{c}{ Classification } & Low & Medium & High & Very High \\
& $(\%)$ & $(\%)$ & $(\%)$ & $\geq 40$ \\
\hline Stunting & $<20$ & $20-29$ & $30-39$ & $\geq 30$ \\
Underweight & $<10$ & $10-19$ & $20-29$ & $\geq 15$ \\
Wasting & $<5$ & $5-9$ & $10-14$ & \\
\hline
\end{tabular}

The results of the present study clearly indicated that, based on the WHO classification of severity of malnutrition (Table 3) ${ }^{19}$, the overall (age and sex combined) prevalence of underweight was very high $(47.07 \%)$ while those of stunting was high $(43.17 \%)$ and wasting was very high $(23.90 \%)$. In terms of sex, the prevalence of wasting among the girls was $22.64 \%$ and among boys was $25.25 \%$. The rates of underweight boys was much higher $(50.51 \%)$ in comparison to the rates of underweight girls $(43.87 \%)$. The rates of stunting in boys were much higher $(44.95 \%)$ than the rates of stunting in girls $(41.51 \%)$. So from overall observation boys were suffering from actual and prolonged food deprivation which results in the higher prevalence of stunting, wasting and underweight than the girls. The results indicate that the prevalence of undernutrition in the boys is higher than the girls although the specific causes are not clear to us.

The prevalence of stunting, wasting and underweight as reported by another recent survey conducted in slum children of Midnapore Town were $47.8 \%, 32.7 \%$ and $63.7 \%$ respectively ${ }^{20}$. This indicated that the prevalence of stunting, wasting and underweight in the present study were lower than the study conducted in the slum children of
Midnapore Town. A lower energy and protein intake was found among the undernourished children when compared with the normal children. Possibly this was the primary cause of undernutrition observed in the present study along with socioeconomic status, hygienic condition, sanitation, life style, education etc appears to be the main cause of this malnutrition. Infection, adverse cultural practices of child care, breast feeding, weaning and some other factors are playing a role in this community. Comprehensive child survival programme and supplementary feeding may be the way out from undernutrition of this community.

In the present study we have covered only a limited population $(17.39 \%)$ of the rural community. We think further detailed research work will reveal the clear picture of undernutrition of preschool children of that geographical area.

\section{Conclusion}

The finding of the present study revealed the widespread prevalence of undernutrition among preschool children of Kankabati grampanchayat, Paschim Medinipur, West Bengal, India. 


\section{Acknowledgements}

The authors acknowledge Dr. Uday Chand Pal (Principal, Raja N.L. Khan Women's College), Dr. Dilip Kumar Nandi (Coordinator, Dept. of Nutrition, Raja N.L. Khan Women's College), Dr. D.P. Dutta (Professor \& Head, Dept. of Medicine, Midnapore Medical College \& Hospital, Midnapore) for their constant support and guidance. The authors thank the guardians of the children for providing their time and cooperation during the study period.

\section{References}

1. International Institute of Population Sciences. National Family Health Survey (NFHS 2). Chhttisgarh (1998-1999). Mumbai 2002.

2. Schofield C., Ashworth A. Why have mortality rates for severe malnutrition remained so high? Bull World Health Organ 1996; 74:223-9.

3. World Health Organization. World Health report. Geneva: The Organization; 2002.

4. Brabin BJ, Coulter JBS. Nutrition-associated disease. In: Cook GC, Zumla AI, editors. Manson's Tropical Diseases. London: Saunders; 2003. pp. 561-80.

5. World Health Organization, United Nations Children's Fund. Joint statement on the management of acute diarrhoea. Geneva: The Organization; 2004

6. Food and Agricultural Organization, United Nations. Undernourishment around the world. In: The state of food insecurity in the world 2004. Rome: The Organization; 2004

7. Sachdev HPS. Assessing child malnutrition some basic issues. Bull Nutr Foundations India 1995; 16:1-5.

8. Mitra M., Tiwary A. Malnutrition in preschool children - A study of Brahmin Rawat and Tali Preschool Children of Raipur. Annual Conference of Indian Society of Human Genetics 16th and 18th Dec 1997 XXIII, New Delhi. 1997.

9. Allen LH, Gillespie SR. What works? A review of the efficiency and effectiveness of nutrition interventions. United Nations. Administrative Committee on Coordination/Sub-Committee on Nutrition, Geneva. Asian Development Bank, Manila. ACC/SCN Nutrition Policy Paper No. 19.
ADB Nutrition and Development series Geneva 2001 No. 5, p. 24-5.

10. Bamji MS. Early nutrition and health - Indian perspective. Current Science 2003; 85: $1137-$ 42.

11. National Nutrition Monitoring Bureau (NNMB and NIN). National Institute of Nutrition, Hyderabad. (c.f. Parvathi, 2001), 1993.

12. Das D, Das A. Statistics in Biology and Physiology 5th ed. Kolkata: Academic Publishers, 2008; p 7-11.

13. Mishra D, Singh HP. Kuppuswami's socioeconomic status scale - A revision. Indian J Pediatr 2003; 70: 273-4. http://dx.doi.org/10.1007/BF02725598

14. Lee RD, Nieman DC. Nutritional assessment. 3rd ed. New York; McGraw Hill; 2003. 163215.

15. World Health Organization. Measuring changes in nutritional status. Geneva: World Health Organization; 1983.

16. Nyaruhucha CNM, Mamiro PS, Kerengi AJ, Shayo NB. Nutritional status of under five children in a pastoral community in Simanjiro district, Tanzania. Tanzan Health Res Bull 2006; 8(1):32-6.

http://dx.doi.org/10.4314/thrb.v8i1.14268

17. International Institute for Population Sciences (IIPS) and ORC Macro International. National Family Health Survey (NFHS-3), 2005-06, Mumbai: IIPS; 2007; p. 267-304.

18. Nandy S., Irving M., Gordon D., Subramanian S.V., \& Davey Smith G., Poverty, child undernutrition and morbidity: new evidence from India. Bulletin of the World Health Organization 2005; 3: 210-6.

19. World Health Organization. Physical Status: The use and Interpretation of Anthropometry. Technical report Series no. 854. WHO: Geneva 1995.

20. Bisai S., Bose K., Dikshit S. Undernutrition among slum Children aged 3-6 years in Midnapore Town, India. The Internet Journal of Biological Anthropology 2009; 2(2): 